\section{$\underset{\substack{\text { hommes } \\ \text { \& migrations }}}{ }$}

\section{Hommes \& migrations}

Revue française de référence sur les dynamiques

migratoires

\section{$1329 \mid 2020$}

Migrations et création littéraire

\title{
Un divan à Tunis
}

Fiction de Manele Labidi (France, 2019)

\section{Mouloud Mimoun}

\section{(2) OpenEdition \\ 1 Journals}

\section{Édition électronique}

URL : https://journals.openedition.org/hommesmigrations/11266

DOI : 10.4000/hommesmigrations. 11266

ISSN : 2262-3353

\section{Éditeur}

Musée national de l'histoire de l'immigration

\section{Édition imprimée}

Date de publication : 1 avril 2020

Pagination : 191-192

ISBN : ISBN 978-2-919040-50-6

ISSN : 1142-852X

\section{Référence électronique}

Mouloud Mimoun, "Un divan à Tunis », Hommes \& migrations [En ligne], 1329 | 2020, mis en ligne le 01 avril 2020, consulté le 04 janvier 2023. URL : http://journals.openedition.org/hommesmigrations/ 11266 ; DOI : https://doi.org/10.4000/hommesmigrations.11266 


\section{Films}

\section{Un divan à Tunis}

de Manele Labidi

(Fiction, France, 2019)

Rares sont les cinéastes

maghrébins ou franco-maghrébins à épouser le cinéma de genre, et en particulier celui de la comédie.

Interpellés par les situations socio-politiques des pays du Maghreb, ils optent volontiers pour la chronique sociale ou le drame, surtout depuis la survenue des révolutions telles que celles qui ont transformé le visage des sociétés algériennes ou tunisiennes. Aussi, Un divan à Tunis constitue-t-il une surprise agréable, récompensée du Prix du public à la dernière Mostra de Venise. Ce qui n'est pas un hasard au pays-roi de la comédie sociale. Celle-ci s'est imposée 

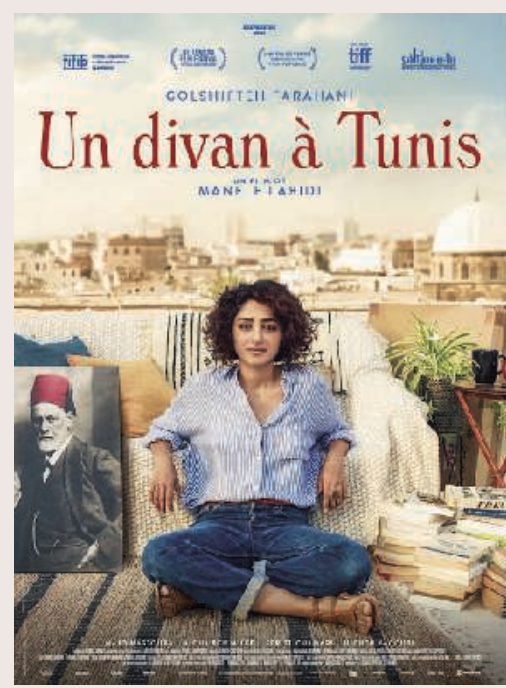

comme le genre dominant du cinéma italien, particulièrement dans les années 1960 à 1980, sous la houlette des Dino Risi, Mario Monicelli, Luigi Comencini ou autre Ettore Scola, avec une génération d'acteurs tout aussi coulés dans le moule de la comédie, qu'ils se nomment Vittorio Gassman, Nino Manfredi, Toto, Ugo Tognazzi et même Marcello Mastroianni.

Manele Labidi, franco-tunisienne, a puisé aux sources du rire à l'italienne pour son tout premier long-métrage, après des études en sciences politiques et en finance, avant d'écrire pour le théâtre, la radio et la télévision. Après son court-métrage Une chambre à moi (2008) - variation tragi-comique autour de l'essai de Virginia Woolf -, elle s'est lancée dans le longmétrage de fiction. Mais Un divan à Tunis révèle surtout un auteur à l'imagination fertile, passé par le programme d'écriture de la Fémis, ce qui a été loin de nuire à la structure d'un scénario d'une grande richesse qui fait la part belle à la comédienne franco-iranienne Golshifteh Farahani, qui survole une distribution rehaussée, comme dans les comédies italiennes, par une galerie de portraits hauts en couleurs. Jusque-là cantonnée à des rôles dramatiques, elle se retrouve ici dans un contre-emploi bienvenu et qui élargit ainsi la palette de son talent de comédienne.
Selma est une psychanalyste qui rejoint sa Tunisie natale pour ouvrir un cabinet dans un quartier populaire, convaincue que Freud est tout indiqué dans un pays quelque peu schizophrène. Il trône d'ailleurs sur le mur avec un portrait de lui où il arbore sur le crâne une chéchia, et sa barbe renvoie d'ailleurs à d'autres barbus tunisiens.

Son style de femme libérée, l'éternelle pompe au bec, et sa guimbarde qu'elle conduit ellemême ne sont pas sans susciter un certain émoi parmi les habitants hauts en couleur de ce quartier populaire où la tradition et la religion sont très prégnantes et agressées par les préceptes de ce Juif athée qu'est Freud. À contrecourant des conventions, Selma s'obstine et se constitue malgré tout une clientèle hétéroclite, qui va d'une coiffeuse exubérante à un imam rejeté et donc en souffrance, en passant par un policier intègre, sans doute sensible au charme de la psy, et un boulanger traumatisé par la découverte de sa part féminine, sans compter la nièce désireuse de quitter la Tunisie et qui ne cesse d'être là quand on ne s'y attend pas.

Selma découvre également les affres d'un maquis administratif à travers la représentante du ministère de la Santé, plus préoccupée par le fait de manger ou de lui vendre des étoffes que de lui faire délivrer l'autorisation d'exercer sa profession, inconnue en Tunisie, malgré les changements et une certaine modernité qui ont accompagné la chute du dictateur Ben Ali.

Tiraillés entre traditions

religieuses et besoin de parler pour se reconstruire, les patients de Selma sont loin de se faire traiter selon les canons de la psychanalyse à l'occidentale.

Golshifteh Farahani est d'autant plus à l'aise dans le rôle de psy qu'après ses déboires en Iran qui l'ont contrainte à l'exil en France, elle a eu elle-même besoin de consulter pour se reconstruire:
"J'avais besoin de paroles et d'écoute, raconte-t-elle. De l'aide d'un spécialiste pour me remettre à raisonner. Ça m'a pris huit ans pour parvenir à recoller les morceaux... »

À propos du personnage de Selma, Manele Labidi, la réalisatrice, explique que "Selma est un personnage atypique même si on le sort du cadre purement tunisien. Je tenais à créer un personnage de cow-boy taiseux, solitaire, mystérieux, viril qui ne cherche pas son salut dans une vie de famille ou une relation amoureuse. Je ne voulais pas non plus en faire un symbole de la liberté des femmes arabes. Elle assume ses choix, sa cigarette vissée au bec sans discours ni revendications. Ce sont ses actes, ses choix de vie et son ouverture à l'altérité qui traduisent sa liberté et sa force. Par ailleurs, alors que ce film traite de la psychanalyse, j'ai fait en sorte de ne pas "psychologiser" le personnage de Selma».

Manele Labidi explique également qu'elle a fait ce film pour traiter de son rapport ambigu avec un pays qu'elle croyait connaître, «dont [elle] maîtrise la langue et les usages mais avec lequel parfois elle se sent en décalage». C'est toute la complexité d'une société en quête d'elle-même qui est au cœur du projet cinématographique teinté d'une légèreté de ton et d'humour. Le pari de raconter cette histoire vue de l'intérieur, avec un regard biculturel franco-tunisien, est gagné, et le cinéma tunisien peut désormais se targuer de compter un talent féminin de plus.

M. M. 